\title{
Vloga čustvenčkov in čustvenih simbolov pri socialnem inženiringu
}

Damjan Fujs*, Simon L. R. Vrhovec in Anže Mihelič Fakulteta za varnostne vede, Univerza v Mariboru

Povzetek: Namen tega prispevka je umestiti rabo čustvenčkov in čustvenih simbolov v komunikaciji, npr. preko socialnih omrežij in SMS-ov, na področje socialnega inženiringa. S sistematičnim pregledom literature v akademskih bazah podatkov Web of Science in Scopus ter oportunističnim iskanjem je bilo identificiranih 40 znanstvenih člankov, ki obravnavajo uporabo čustvenčkov in čustvenih simbolov pri socialnem inženiringu. Raba čustvenčkov in čustvenih simbolov v komunikaciji je oblika neposredne komunikacije, saj pošiljatelj z njimi neposredno vpliva na prejemnika. Čustvenčki in čustveni simboli so univerzalno orodje, ki ga na podoben način razumejo vsi uporabniki komunikacijskih tehnologij ne glede na demografske značilnosti. Večina identificiranih študij uporablja kvantitativni pristop ter obsega različna področja, kot so marketing, psihologija, sociologija itd. Pričujoči prispevek predstavlja enega prvih sistematičnih pregledov literature, ki obravnavajo čustvenčke in čustvene simbole v kontekstu socialnega inženiringa. Rezultati prispevka nudijo temelje za nadaljnje, predvsem kvalitativne raziskave.

Ključne besede: komunikacija, čustvenčki, družbeni inženiring, ribarjenje, prepričevanje

\section{The role of emojis and emoticons in social engineering}

\author{
Damjan Fujs ${ }^{*}$, Simon L. R. Vrhovec and Anže Mihelič \\ Faculty of Criminal Justice and Security, University of Maribor, Slovenia
}

\begin{abstract}
The purpose of this paper is to place the use of emojis and emoticons in communication, e.g., on social networks and with SMSs, to the field of social engineering. With a systematic literature survey in academic databases Web of Science and Scopus, and opportunistic search, 40 scientific papers about emojis and emoticons in social engineering were identified. The use of emojis and emoticons in communication is a form of direct communication as the sender directly influences the recipient. Emojis and emoticons are a universal tool that is understood by all communication technology users regardless of their demographics. Most of the analyzed studies employ a quantitative approach and span different research areas, such as marketing, psychology, sociology, etc. This paper represents one of the first systematic literature reviews that deal with emojis and emoticons in the context of social engineering. The findings of this paper may serve as a basis for further, especially qualitative research.
\end{abstract}

Keywords: communication, emojis, social engineering, phishing, persuasion

\footnotetext{
${ }^{*}$ Naslov/Address: Damjan Fujs, Fakulteta za varnostne vede, Univerza v Mariboru, Kotnikova 8, 1000 Ljubljana, e-mail: damjan.fujs@fri.uni-lj.si

Članek je licenciran pod pogoji Creative Commons Attribution 4.0 International licence. (CC-BY licenca). The article is licensed under a Creative Commons Attribution 4.0 International License (CC-BY license).
} 
Verjetno ni uporabnika socialnih omrežij in mobilnih naprav, ki ne bi nikoli v spletni komunikaciji vsaj enkrat uporabil čustvenčkov (angl. emoji) ali čustvenih simbolov (angl. emoticon). Čustvenčki so grafični simboli, ki so namenjeni obogatitvi tipkane besede. So virtualno orodje za izkazovanje čustev, pri čemer sta njihovo razumevanje in uporaba univerzalna. Na primer, mladi razumejo in uporabljajo čustvenčke na podoben način kot starejši (Alshenqeeti, 2016). Za čustvenčke je leto 2014 predstavljalo enega izmed prelomnih let. Začeli so se namreč pojavljati čustvenčki, ki predstavljajo netipično hrano (npr. tradicionalno afriško kulinariko), dodane so bile zastave držav sveta (npr. obstajala je izraelska, ne pa tudi palestinska), dodani so bili različni tipi družin itd. (Pardes, 2018). Pojavili so se tudi novi načini izražanja čustev, npr. pojavil se je sredinec, pojavili so se čustvenčki, ki prikazujejo raznolikost kultur itd. (Davis, 2014).

O dejstvu, da so čustvenčki in čustveni simboli pomemben del tekstovne komunikacije priča tudi podatek, da je leta 2015 čustvenček prvič v zgodovini postal "beseda leta" v slovarju Oxford Dictionaries (Wang, 2015) in da je čustvenčkom namenjenih že več spletnih enciklopedij (npr. emojipedia.org, emojis.wiki, emojifoundation.org), kjer so posamezni čustvenčki predstavljeni in opisani z različnih vidikov, kot so novosti, kategorije in platforme. $Z$ namenom promoviranja uporabe čustvenčkov in občutkov, ki jih vzbujajo, je določeno tudi praznovanje svetovnega dneva čustvenčkov - 17. julij (Emojipedia.org, 2019). V namen spremljanja rabe čustvenčkov v realnem času je bila razvita tudi spletna aplikacija emojitracker.org, ki omogoča vpogled v rabo čustvenčkov na socialnem omrežju Twitter.

Čustvenčki pa niso namenjeni izključno vizualni obogatitvi besedila. V digitalni komunikaciji služijo tudi kot orodje za prikrivanje dejanskih občutij in pretvarjanje (Stark in Crawford, 2015), kar omogoča nove možnosti prevar. S pomočjo čustvenčkov lahko namreč napadalci poskušajo vplivati na potencialno žrtev (prejemnika sporočila), da bi izdala zaupne informacije, ki jih je mogoče uporabiti $\mathrm{v}$ zlonamerne namene (Njenga, 2017). Socialni inženiring (angl. social engineering) je napad na potencialno žrtev s pomočjo zlorabe zaupanja. Pri tem napadalec $\mathrm{s}$ prevaro pridobi zaupanje uporabnika, ki nato izda svoje osebne podatke ali si namesti škodljivo programsko opremo na svojo napravo (npr. računalnik ali mobilni telefon; Vrhovec, 2016). Slika 1 prikazuje vpliv čustvenčkov na atmosfero pogovora pri poteku primera napada $\mathrm{z}$ uporabo socialnega inženiringa.

Kot je razvidno iz primera na sliki 1, uporaba čustvenčkov ustvari drugačno atmosfero pogovora, ki vzbudi različno interpretacijo sicer enakega besedila. Besedilo A: ̌̌e na samem začetku pri pozdravu vidimo nasmejanega čustvenčka, ki v nas vzbudi občutke veselja. Nato nas čustvenčki rahlega potu in prošnje že zaradi večkratnih ponovitev prepričajo, da je pomoč nujno potrebna ter da nas oseba resnično potrebuje. Besedilo B: Prejemnik si veliko lažje razlaga prošnjo za pomoč kot posledico neodgovornosti pošiljatelja sporočila in ima zato manj empatije do pošiljatelja.

Kljub temu, da imajo lahko čustvenčki in čustveni simboli pomemben učinek na potek in uspešnost napadov $\mathrm{z}$ uporabo socialnega inženiringa, pa je le malo raziskav na temo uporabe čustvenčkov in čustvenih simbolov pri teh napadih. Namen tega prispevka je zapolniti to vrzel $s$ sistematičnim pregledom znanstvene literature ter umestiti rabo čustvenčkov in čustvenih simbolov v komunikaciji na področje socialnega inženiringa. Predpostavljamo, da imajo čustvenčki zaradi svoje razširjenosti in široke možnosti uporabe vse pomembnejšo vlogo v digitalnem izražanju, saj vstavljanje čustvenčkov ne omogočajo le najpogostejši kanali komuniciranja, kot so SMS in socialna omrežja, pač pa tudi domala vsaka aplikacija, ki omogoča izmenjavo besedil. V tem prispevku iščemo odgovor na raziskovalno vprašanje "Kako lahko čustvenčki in čustveni simboli vplivajo na uspešnost spletnih napadov s socialnim inženiringom?”

$\mathrm{V}$ prispevku se torej osredotočamo na to, ali čustvenčki in čustveni simboli pripomorejo $\mathrm{k}$ (ne)varnemu delovanju in vedenju med komuniciranjem $\mathrm{v}$ kibernetskem prostoru ter ali so lahko čustvenčki in čustveni simboli orodje za večjo uspešnost napadov s socialnim inženiringom.

\section{Teoretična izhodišča}

Čustvenčki so relativno nov pojav na področju tekstovnega komuniciranja, saj so bili ustvarjeni leta 1999. Izhajajo iz čustvenih simbolov, ki so se prvič pojavili že leta 1982 (Grannan, 2019). Prve raziskave na tem področju so se nanašale na čustvene simbole (Derks, 2008; Wolf, 2000; Xu idr., 2007), šele kasneje, predvsem s pojavom mobilnih tehnologij, pa se je usmeritev razširila tudi na pojav čustvenčkov (Burge, 2013; Marengo idr., 2017; Stark in Crawford, 2015). Pri čustvenih simbolih, včasih imenovanih tudi smejkoti (angl. smiley), gre za simbole iz različnih kombinacij znakov, ki bralca spominjajo na čustva. Čustvenčki pa so bolj grafično dodelani oz. gre za sličice, ki so prvotno namenjeni prikazovanju čustvenih simbolov oz. čustev (Grannan, 2019), lahko pa služijo tudi kot orodje za prikaz drugih podob, kot so šport, živali, predmeti itd. Danes so čustvenčki neločljiv del komunikacije na socialnih omrežjih tako v zasebnih in skupinskih komunikacijskih oknih kot tudi v odzivih na objavljene vsebine (tj. v smislu vnaprej ponujenih možnosti odzivanja). Facebook je sprva omogočal zgolj všečkanje objav, leta 2016 pa so dodali še druge čustvene reakcije (npr. žalost, jeza, smeh), s katerimi so želeli uporabnikom omogočiti različne oblike sočustvovanj (D’Onfro, 2016). Leta 2019 so te čustvene upodobitve grafično posodobili, kar bralcu in uporabniku daje še večji občutek poistovetenja

\section{Zdravo $\ddot{*}^{\wedge}$}

Bi mi lahko posodil tvoje do elektronskih virov? ث d.d.d.

Svojega še nisem prevzel - 2.9 pa se mi mudi

Oे diplomirat. $\quad$ 망 dy SS니를

A geslo za oddaljen dostop

\section{Zdravo}

Bi mi lahko posodil tvoje geslo za oddaljen dostop do elektronskih virov?

Svojega še nisem prevzel pa se mi mudi diplomirat.

\section{B}

Slika 1. Primer napada z uporabo socialnega inženiringa z (A) in brez uporabe čustvenčkov (B). 
z objavo (Hutchinson, 2019). Med najrazličnejšimi simboli velja posebej omeniti tudi kaomoji, ki so podobno kot čustveni simboli ustvarjeni s kombinacijo znakov, a predstavljajo bistveno kompleksnejše pojme, scenarije in sličice. Slika 2 prikazuje razlike med zgoraj omenjenimi pojmi.

Da bi lahko ocenili, koliko in če sploh lahko čustveni simboli in čustvenčki pripomorejo k uspešni izvedbi napadov s socialnim inženiringom, je potrebno najprej opredeliti ta pojem. Socialni inženiring lahko opredelimo kot orodje oz. manipulativno tehniko, s pomočjo katere pridobijo napadalci od ljudi želene zaupne informacije (Workman, 2008). Napadi socialnega inženiringa so lahko različnega tipa (npr. socio-tehnični, tehnični, fizični in socialni), potekajo preko različnih kanalov (npr. socialna omrežja, telefon, epošta, spletne strani) in preko različnih operatorjev (npr. človek, programska oprema). Pri tem si napadalci pomagajo z različnimi vektorji napada, kot so brskanje po smeteh, gledanje čez ramo, zvabljanje in zavajanje (Krombholz idr., 2015). Med najpogostejše vrste socialnega inženiringa spada zvabljanje oz. ribarjenje (angl. phishing), ki se navadno izvaja $\mathrm{z}$ namenom pridobitve občutljivih podatkov s primarnim namenom pridobitve materialnih koristi. Najpogosteje gre za masovno pošiljanje e-pošte z lažnim predstavljanjem. Bolj sofisticirano, $z$ več elementi socialnega inženiringa in tudi bistveno učinkovitejše, pa je usmerjeno zvabljanje (angl. spear phishing), kjer je za razliko od navadnega zvabljanja tarča skrbno izbrana, napad pa natančno načrtovan (Mihelič idr., 2019). To pomeni, da napadalci pri preprostem zvabljanju ne izbirajo žrtev vnaprej, temveč stavijo na to, da z masovnim pošiljanjem kolikor toliko naključnim prejemnikom identificirajo bolj ranljive posameznike, medtem ko pri usmerjenem zvabljanju napadalci skrbno izberejo tarčo in skušajo vzpostaviti zadostno mero zaupanja $\mathrm{v}$ njihovo verodostojnost, kar se doseže s skrbnim vnaprejšnjim

\section{čustveni simboli}

(1)

\section{$\left(د_{0}^{\circ} \smile \dot{\Delta}_{0}\right) \supset$ -}

Slika 2. Primerjava čustvenih simbolov, čustvenčkov in kaomojijev. zbiranjem informacij. Tipičen primer bi bil, da napadalec naveže stik z računovodstvom izbranega podjetja, da bi zbral čim več relevantnih informacij o podjetju in zaposlenih.

\section{Metoda}

Da bi odgovorili na raziskovalno vprašanje in ugotovili, kako lahko čustvenčki in čustveni simboli vplivajo na uspešnost napadov s socialnim inženiringom, smo izvedli sistematičen pregled literature. Pregled literature je bil opravljen v bibliografskih bazah podatkov Web of Science in Scopus med 25.3.2019 in 28.4.2019. Prvi korakje predstavljalo napredno iskanje, ki je bilo opravljeno s ključnimi besedami in njihovimi kombinacijami: social, engineering, emoji, behavior, behaviour, psychology, phishing, emotion, smiley, use, hacking in emoticon. Na podlagi teh iskalnih kriterijev je bilo vrnjenih 177 zadetkov $\left(N_{\text {Web_of_Science }}=119, N_{\text {Scopus }}=58\right)$.

$\mathrm{V}$ drugem koraku so bili izbrani prispevki na podlagi vključitvenih in izključitvenih kriterijev. Vključitveni kriteriji: jezik prispevka je angleščina, prispevek je bil objavljen leta 2014 ali kasneje, prispevek je tematsko ustrezen (tj. neposredna obravnava tematike čustvenčkov ali čustvenih simbolov in vsaj posredna relevantnost za napade s socialnim inženiringom), prispevek je članek $\mathrm{v}$ znanstveni reviji ali v zborniku znanstvene konference. Izključitveni kriteriji: jezik prispevka ni angleščina, prispevek je bil objavljen leta 2013 ali prej, prispevek ni tematsko ustrezen, prispevek ni članek $\mathrm{v}$ znanstveni reviji ali $\mathrm{v}$ zborniku znanstvene konference. Po pregledu naslovov in povzetkov je bilo na podlagi predstavljenih kriterijev izločenih 122 prispevkov. Preostalih 55 prispevkov je bilo pregledanih v celoti. Po izključitvi še 18 prispevkov je bilo $\mathrm{v}$ podrobno analizo vključenih 37 prispevkov. Sistematični pregled literature je bil dopolnjen z oportunističnim iskanjem, da bi zajeli čim več relevantnih virov. Na ta način so bili vključeni še trije dodatni viri, na koncu pa je bilo v podrobno analizo vključenih 40 prispevkov.

Podrobna analiza prispevkov je vključevala identifikacijo uporabljene raziskovalne metode (npr. eksperiment, analiza besedil, spletna anketa), lastnosti vzorca (npr. velikost in specifike preučevane populacije) in ključne ugotovitve prispevkov glede čustvenčkov in čustvenih simbolov ter njihove relevantnosti za napade s socialnim inženiringom.

\section{Rezultati}

Na podlagi analizirane $\mathrm{v}$ zadnjih petih letih objavljene znanstvene literature na področju čustvenčkov in čustvenih simbolov, ki je relevantna za napade s socialnim inženiringom, lahko podamo splošno ugotovitev, da je tematika skopo raziskana. Raziskovalci so se posluževali osmih raziskovalnih metod: spletna anketa (15 prispevkov), eksperiment (11 prispevkov), analiza besedil (7 prispevkov), pregled literature (4 prispevkov), opazovanje (1 prispevek), intervju (1 prispevek), študija primera (1 prispevek) in sistematični pregled literature (1 prispevek). Analiza besedil vključuje različne vire besedil s čustvenčki ali čustvenimi simboli, kot so povedi s čustvenčki ali čustvenimi simboli, tviti (besedila na socialnem omrežju Twitter) in SMS-i (mobilna sporočila). Rezultati sistematičnega pregleda literature so prikazani $\mathrm{v}$ tabeli 1. 
Tabela 1. Raziskovalna metoda, lastnosti vzorca in ključne ugotovitve vključenih prispevkov

\begin{tabular}{|c|c|c|c|}
\hline Vir & Metoda & Vzorec & Ključne ugotovitve \\
\hline $\begin{array}{l}\text { Weiß, Gutzeit, Rodrigues, Mussel in } \\
\text { Hewig, } 2019\end{array}$ & Eksperiment & $\begin{array}{l}N=60 \text { študentov }(56,7 \% \\
\text { žensk) }\end{array}$ & $\begin{array}{l}\text { Čustvenčki, ki prikazujejo žalost (angl. sad } \\
\text { emoji), izzovejo burnejše reakcije možganov } \\
\text { v primerjavi z veselimi ali nevtralnimi } \\
\text { čustvenčki. }\end{array}$ \\
\hline $\begin{array}{l}\text { Aldunate, Villena-González, Rojas- } \\
\text { Thomas, López in Bosman, } 2018\end{array}$ & Eksperiment & $\begin{array}{l}N=74 \text { dodiplomskih } \\
\text { študentov ( } 70,3 \% \text { žensk) }\end{array}$ & $\begin{array}{l}\text { Za pravilno interpretacijo konteksta } \\
\text { informacije je pri medosebni komunikaciji } \\
\text { treba imeti na voljo čim več informacij (npr. } \\
\text { telesna govorica in obrazna mimika). Podobno } \\
\text { je v virtualnem okolju. Poleg čustvenčkov } \\
\text { je za pravilno interpretacijo treba pozornost } \\
\text { nameniti tudi besedilu in kontekstu. }\end{array}$ \\
\hline Duan, Xia in Van Swol, 2018 & Eksperiment & $N=127$ & $\begin{array}{l}\text { Za doseganje boljše pozornosti bralca je pri } \\
\text { spletnem svetovanju pomembna ustrezna izbira } \\
\text { čustvenih simbolov. }\end{array}$ \\
\hline Lin in Chen, 2018 & Eksperiment & $N=42$ udeležencev & $\begin{array}{l}\text { Ne-intimna oz. distancirana medosebna spletna } \\
\text { komunikacija vodi do uporabe bolj abstraktnih } \\
\text { oz. geometričnih čustvenih simbolov. }\end{array}$ \\
\hline F. Takahashi in Kawabata, 2018 & Eksperiment & $\begin{array}{l}N=40 \text { študentov in } \\
\text { sodelavcev fakultete } \mathrm{z} \\
\text { zdravim vidom }\end{array}$ & $\begin{array}{l}\text { Pozitivna čustva so povezana s svetlejšimi } \\
\text { in bolj nasičenimi barvami, medtem ko so } \\
\text { negativna čustva povezana s temnejšim } \\
\text { odtenkom svetlobe. }\end{array}$ \\
\hline Bordbar, Memari in Asadi, 2017 & Eksperiment & $\begin{array}{l}N=32 \text { udeležencev, } 16 \\
\text { mobilnih pogovorov, } 1.398 \\
\text { sporočil }\end{array}$ & $\begin{array}{l}\text { Pogajalci, ki so v besedilo vključili čustvene } \\
\text { simbole so prej dosegli dogovor v primerjavi s } \\
\text { tistimi, ki v besedilih čustvenih simbolov niso } \\
\text { uporabljali. }\end{array}$ \\
\hline $\begin{array}{l}\text { Salgado-Montejo, Salgado, } \\
\text { Alvarado in Spence, } 2017\end{array}$ & Eksperiment & $N=136$ prostovoljcev & $\begin{array}{l}\text { Preproste linije in geometrične oblike lahko } \\
\text { služijo kot orodje za sporočanje jeze, veselja, } \\
\text { žalosti in presenečenja. }\end{array}$ \\
\hline $\begin{array}{l}\text { K. Takahashi, Oishi in Shimada, } \\
2017\end{array}$ & Eksperiment & $\begin{array}{l}N=91 \text { (30 Kameruncev, } 37 \\
\text { Tanzanijcev, } 24 \text { Japoncev) }\end{array}$ & $\begin{array}{l}\text { Prepoznavanje čustev iz čustvenih simbolov ni } \\
\text { kulturno univerzalno. Kamerunci in Tanzanijci } \\
\text { imajo težave s prepoznavanjem čustev iz } \\
\text { čustvenih simbolov. }\end{array}$ \\
\hline Kinard in Kinard, 2013 & Eksperiment & $N=168$ potrošnikov & $\begin{array}{l}\text { Personalizirana sporočila ali čustveni simboli } \\
\text { na gostilniških računih znižujejo odstotek } \\
\text { napitnine. }\end{array}$ \\
\hline Ibáñez, 2011 & Eksperiment & $N=36(66,7$ \% moških $)$ & $\begin{array}{l}\text { Preprosti simboli v primerjavi z velikim } \\
\text { številom čustvenih simbolov ustvarijo večja } \\
\text { pričakovanja - odražajo inteligenco. }\end{array}$ \\
\hline Willoughby in Liu, 2018 & $\begin{array}{l}\text { Eksperiment in } \\
\text { spletna anketa }\end{array}$ & $N=426(68,3 \%$ žensk $)$ & $\begin{array}{l}\text { Besedila o zdravju in zdravstvu so brez } \\
\text { čustvenčkov bolj kredibilna in vredna } \\
\text { zaupanja. }\end{array}$ \\
\hline $\begin{array}{l}\text { Marder, Houghton, Erz, Harris in } \\
\text { Javornik, } 2019\end{array}$ & Spletna anketa & $N=902$ študentov & $\begin{array}{l}\text { Dodajanje čustvenih simbolov v tekst } \\
\text { pripomore institucijam (univerzam) doseg } \\
\text { širšega občinstva. }\end{array}$ \\
\hline Tseng in Hsieh, 2019 & Spletna anketa & $\begin{array}{l}N=202 \text { uporabnikov SMS } \\
(65,3 \% \text { žensk })\end{array}$ & $\begin{array}{l}\text { Psihološko lastništvo nad čustvenimi simboli } \\
\text { pozitivno vpliva na užitek uporabe SMS v } \\
\text { okviru komunikacije. }\end{array}$ \\
\hline Grieve, Moffitt in Padgett, 2019 & Spletna anketa & $\begin{array}{l}N=210 \text { študentov }(80,9 \% \\
\text { Žensk) }\end{array}$ & $\begin{array}{l}\text { Študenti, ki so na vrnjenih domačih nalogah } \\
\text { dobili čustveni simbol, ocenjujejo ocenjevalca } \\
\text { kot bolj ekstrovertiranega, razumevajočega in } \\
\text { odprtega. }\end{array}$ \\
\hline $\begin{array}{l}\text { Thomson, Kluftinger in Wentland, } \\
2018\end{array}$ & Spletna anketa & $N=693(77,8$ \% žensk $)$ & $\begin{array}{l}\text { Uporaba spolno sugestivnih čustvenčkov } \\
\text { nakazuje na ekstrovertiranost in število } \\
\text { priložnostnih spolnih partnerjev. }\end{array}$ \\
\hline $\begin{array}{l}\text { Glikson, Cheshin in van Kleef, } \\
2018\end{array}$ & Spletna anketa & $N=203$ (76 \% žensk) & $\begin{array}{l}\text { V primerjavi z moškimi ženske uporabljajo } \\
\text { čustvene simbole pogosteje. V okviru službene } \\
\text { korespondence imajo čustvenčki negativen } \\
\text { vpliv, realen nasmeh sicer pozitiven. }\end{array}$ \\
\hline
\end{tabular}




Prada idr., $2018 \quad$ Spletna anketa $\quad N=474$ (72,6 \% žensk)

Li, Chan in Kim, 2019

Spletna anketa

$N=909$ spletnih nakupovalcev (77 \% žensk)

Rodrigues idr., 2017

Spletna anketa

$N=505$ (14\% žensk)

\begin{tabular}{lll}
\hline Cheng, 2017 & Spletna anketa & $\begin{array}{l}N=140 \text { študentov (57,1 \% } \\
\text { žensk) }\end{array}$ \\
\hline Matsui in Kato, 2017 & Spletna anketa & $N=37$ (59,5 \% žensk)
\end{tabular}

\begin{tabular}{lll}
\hline Riordan, 2017 & Spletna anketa & $N=1502$ (starost 18 do 78) \\
\hline Marengo idr., 2017 & Spletna anketa & $N=234$ (62 \% žensk)
\end{tabular}

Lohmann, Pyka in Zanger, $2017 \quad$ Spletna anketa $\quad N=1745$ žensk

\begin{tabular}{lll}
\hline Huang, Yen in Zhang, 2008 & Spletna anketa & $N=216$ študentov \\
\hline Njenga, 2017 & Študija primera & $\begin{array}{l}N=20 \text { napadov socialnega } \\
\text { inženiringa }\end{array}$
\end{tabular}

Peng, Hu in Dang, 2019

Opazovanje

$N=387$ (135 depresivnih)

Happ, Melzer in Steffgen, $2016 \quad$ Intervju

$N=1206($ starost 12 do 74$)$
Ženske so napram moškim bolj naklonjene uporabi čustvenčkov, medtem ko so mladi naklonjeni tako čustvenčkom, kot čustvenim simbolom.

Stranke zaposlene obravnavajo kot bolj prijazne vendar kot manj kompetentne, če v komunikaciji z njimi uporabljajo čustvene simbole.

Čustvenčki so napram čustvenim simbolom smatrani kot okras. Ženske raje uporabljajo čustvenčke kot moški.

Čustveni simboli hitreje vzbudijo pozornost in pozitivne občutke napram golemu besedilu.

Izbira določenih čustvenih simbolov lahko izraža individualno značilnost.

Čustvenčki odpravljajo dvoumnosti sporočila, včasih celo bolje kot dodatne besede.

Na podlagi rabe čustvenčkov je mogoče določiti osebnost.

Negativni čustveni simboli močno zmanjšujejo veselje in dvigujejo nivo zaskrbljenosti. Podobno je tudi pri pozitivnih čustvenih simbolih, ki nekoliko znižujejo nivo veselja in rahlo dvigujejo nivo zaskrbljenosti.

Čustvenčki neposredno vplivajo na užitek, ta pa na osebne odnose.

Žrtev je mogoče lažje prepričati, če so v besedilu prisotni čustvenčki. Če v besedilu ni čustvenčkov je treba vložiti več časa za prepričevanje.

Nezavedne aktivnosti, kot so frekvenca in čas objavljanja čustvenčkov, lahko razkrivajo osebnost.

Več kot tretjina intervjuvancev $(38,6 \%)$ je v dveh minutah razkrilo svoje geslo popolnemu neznancu (intervjuvarju) $\mathrm{v}$ zameno za čokolado. Če ima oseba na sebi logotip spoštovane institucije to pripomore $\mathrm{k}$ zmanjšanju socialnih ovir pri razkrivanju informacij.

\begin{tabular}{|c|c|c|c|}
\hline $\begin{array}{l}\text { Feldman, Aragon, Chen in Kroll, } \\
2018\end{array}$ & Analiza besedil & $N=290.306$ sporočil & $\begin{array}{l}\text { Skozi daljši čas uporabniki zmanjšujejo nabor } \\
\text { raznolikosti čustvenih simbolov. }\end{array}$ \\
\hline Luangrath, Peck in Barger, 2017 & Analiza besedil & $\begin{array}{l}N=859 \text { tvitov, ki poleg } \\
\text { besedila vsebujejo ne- } \\
\text { tekstovne elemente }\end{array}$ & $\begin{array}{l}\text { Ljudje z dominantno desno možgansko } \\
\text { hemisfero pogosteje uporabljajo čustvenčke. }\end{array}$ \\
\hline Qiu, Feng in Yang, 2017 & Analiza besedil & $\begin{array}{l}N=18 \text { povedi zapisanih } \\
\text { samo s čustvenčki }\end{array}$ & $\begin{array}{l}\text { Z ustrezno rabo »emoji« slovničnih pravil } \\
\text { lahko uporabniki podajo zelo točne in slikovite } \\
\text { izjave - bolj interpretativne v primerjavi z } \\
\text { golim besedilom. }\end{array}$ \\
\hline $\begin{array}{l}\text { Na'aman, Provenza in Montoya, } \\
2017\end{array}$ & Analiza besedil & $\begin{array}{l}N=567 \text { tvitov, ki vsebujejo } \\
\text { čustvenčke ( } 887) \text { ali } \\
\text { čustvene simbole }\end{array}$ & $\begin{array}{l}\text { Čustvenčki se uporabljajo v dobesednem ali } \\
\text { prenesenem pomenu (npr. roža kot dejanska } \\
\text { roža ali kot znak ljubezni). }\end{array}$ \\
\hline $\begin{array}{l}\text { Prasad, Sanjana, Bhat in Harish, } \\
2017\end{array}$ & Analiza besedil & $N=2000$ tvitov & $\begin{array}{l}\text { Model analize tvitov s čustvenčki in čustvenimi } \\
\text { simboli omogoča detekcijo sarkastičnih besedil } \\
\text { v realnem času. }\end{array}$ \\
\hline Oleszkiewicz idr., 2017 & Analiza besedil & $\begin{array}{l}N=86.702 \text { uporabnikov } \\
\text { Facebooka }\end{array}$ & $\begin{array}{l}\text { Z leti pada raba čustvenih simbolov za } \\
\text { posodabljanje statusa na socialnih omrežjih. } \\
\text { Ženske pogosteje uporabljajo čustvene } \\
\text { simbole. }\end{array}$ \\
\hline $\begin{array}{l}\text { Shaikh, Lalingkar, Barach in } \\
\text { Feldman, } 2017\end{array}$ & Analiza besedil & $\begin{array}{l}N=2 \text { milijona tvitov } \mathrm{v} \\
\text { roku } 24 \text { ur po terorističnem } \\
\text { napadu v Parizu } 2015\end{array}$ & $\begin{array}{l}\text { Geografska razdalja od dogodka vpliva na stil } \\
\text { pisanja na Twitterju. }\end{array}$ \\
\hline
\end{tabular}




\begin{tabular}{|c|c|c|c|}
\hline Tang in Hew, 2018 & $\begin{array}{l}\text { Sistematični pregled } \\
\text { literature }\end{array}$ & $N=50$ študij & $\begin{array}{l}\text { Ni še znano, ali čustvenčki in čustveni simboli } \\
\text { neposredno vodijo uporabnika k želenemu } \\
\text { cilju. }\end{array}$ \\
\hline Bich-carrière, 2019 & Pregled literature & & $\begin{array}{l}\text { Težave pri interpretaciji čustvenčkov se } \\
\text { pojavljajo tudi na sodišču, saj se pojavljajo tudi } \\
\text { v uradnih kazenskih spisih. }\end{array}$ \\
\hline Elder, 2018 & Pregled literature & & $\begin{array}{l}\text { Čustvenčki so orodje za izkazovanje čustev, pri } \\
\text { ljudeh lahko dajejo občutek altruizma. }\end{array}$ \\
\hline Santos in Maia, 2018 & Pregled literature & & $\begin{array}{l}\text { Pri raziskovanju Twitterja se dandanes } \\
\text { raziskovalci preveč nekritično opirajo na } \\
\text { šest osnovnih čustev po Ekmanu in Friesenu } \\
\text { (1971), čeprav nista nikoli trdila da jih obstaja } \\
\text { samo in zgolj šest. Izziv pri interpretaciji } \\
\text { besedil na socialnem omrežju Twitter je } \\
\text { ugotavljanje sarkazma oz. ironije. Čustvenčke } \\
\text { in besedilo je treba interpretirati kot celoto, da } \\
\text { bi lahko ugotovili, ali je neki zapis ironičen oz. } \\
\text { šaljiv. }\end{array}$ \\
\hline Hankerson idr., 2016 & Pregled literature & $\begin{array}{l}N=6 \text { primerov } \\
\text { diskriminatornih tehnologij }\end{array}$ & $\begin{array}{l}\text { Čustvenčki lahko služijo tudi kot orodje } \\
\text { rasnega razlikovanja (npr. čustvenčki, ki } \\
\text { predstavljajo samo belo raso). }\end{array}$ \\
\hline
\end{tabular}

Čustvenčki in čustveni simboli vplivajo na čustva osebe (Cheng, 2017), saj so v svojem bistvu bolj "človeški” kot "digitalni". Niso zgolj sredstvo komuniciranja s simboli, temveč orodje, ki dodatno obogati besedilo in poveča bralčevo pozornost (Elder, 2018; Riordan, 2017). Tako so tudi sredstva manipulacije (Bordbar idr., 2017) in sredstva za ugotavljanje individualnih značilnosti (Marengo idr., 2017; Matsui in Kato, 2017). Odgovoru na raziskovalno vprašanje se je najbolj približal Njenga (2017), ki je čustvenčke s pomočjo antropomorfne analize umestil na področje socialnega inženiringa ter jih predstavil kot orodje za uspešnejšo izvedbo napada, kar nakazuje na to, da so čustvenčki lahko učinkovito orodje za prepričevanje ljudi in pridobivanje podatkov. V eksperimentu med študenti so se napadalci poslužili metod socialnega inženiringa, da bi od 20 naključnih študentov dobili vsaj eno pomembno informacijo (številko bančnega računa, telefonsko številko, rezultat izpita, številko osebne izkaznice ali poljubno vstopno geslo). Pri treh uspešnih napadih (15\%) je bila uporabljena največja frekvenca čustvenčkov (Njenga, 2017).

\section{Razprava}

$\mathrm{V}$ tem prispevku predstavljen sistematični pregled literature je eden izmed prvih na področju vpliva rabe čustvenčkov in čustvenih simbolov $\mathrm{v}$ okviru socialnega inženiringa. Prispevek nudi več teoretičnih in praktičnih implikacij. Raziskave nakazujejo na to, da različni čustvenčki oz. čustveni simboli različno vplivajo na zaznavanje s strani prejemnika (Campbell, 2019; Churches idr., 2009; Lohmann idr., 2017; Peng idr., 2019; Prada idr., 2018; Woolford idr., 2011). Oblike, ki spominjajo na obraz $\mathrm{z}$ nasmehom, na osebo delujejo podobno kot nasmeh $\mathrm{v}$ živo. Posledično lahko primerna in zmerna raba čustvenčkov pripomoreta $\mathrm{k}$ uspešnejšemu doseganju zlonamernih ciljev, saj lahko napadalec uporablja čustvenčke za vzpostavitev pristnejšega intimnega odnosa s potencialno žrtvijo, kar olajša pot do pridobitve podatkov. Za razumevanje pomembnosti uporabe čustvenčkov vidika socialnega inženiringa je pomembno védenje, da tudi pogajalci za pridobivanje podatkov pogosto uporabljajo (žalost vzbujajoče) čustvenčke (Bordbar idr., 2017). Vse pogosteje se uporabljajo tudi kot del marketinških strategij spletnih trgovin, npr pri komunikaciji s strankami. Kupci namreč menijo, da osebe za pomoč strankam, ki uporabljajo čustvenčke, delujejo bolj prijazne kot tiste, ki jih ne (Li, Chan in Kim, 2019). Na podlagi tega lahko sklepamo, da so tako tisti čustvenčki, ki nakazujejo na veselje, kot tudi tisti, ki nakazujejo na žalost, lahko sredstvo manipulacije in orodje za dosego ciljev napadov $\mathrm{z}$ uporabo socialnega inženiringa.

Uspešni napadi $\mathrm{z}$ uporabo socialnega inženiringa običajno vključujejo več korakov in večina se jih vrši $\mathrm{v}$ okviru sinhrone komunikacije (npr. preko telefona ali pogovora v živo; Bullée idr., 2018). Ker komunikacija v živo (angl. face-to-face) napadalcu omogoča, da potencialno žrtev bolje spozna, v realnem času spremlja njen čustveni odziv in da žrtev nima veliko časa za razmislek, napadalci pogosto najprej vzpostavijo stik s potencialno žrtvijo v resničnem svetu. Začetno zaupanje lahko napadalci ustvarijo v živo ali na daljavo (telefon, (video) pogovor preko spleta), s čimer potencialne žrtve lahko slišijo vsaj glas nekoga na drugi strani (Bullée idr., 2018). Pisana besedila to skoraj povsem onemogočajo, razumevanje besedila pa je tako povsem odvisno od interpretacije posameznika. Na tem mestu imajo čustvenčki in čustveni simboli ključno dodano vrednost, saj lahko nadomestijo ali celo presežejo vpliv na čustva potencialne žrtve, ki ga lahko napadalci dosežejo s komunikacijo v živo.

Vsesplošna uporaba čustvenčkov je primerna zgolj za osebno komunikacijo. Čeprav s čustvenčki pošiljatelj nakazuje nasmeh oz. veselje, so $\mathrm{v}$ uradni in službeni komunikaciji trenutno zaznani kot neprimerni, saj odražajo neprofesionalnost in posledično (lahko) vzbudijo sum $\mathrm{v}$ pozitivno zaznavo pošiljateljeve kompetentnosti (Glikson 
idr., 2018). Ne velja pa to za vse situacije. Komunikacija visokošolskih učiteljev s študenti je sicer formalna, a lahko z uporabo čustvenčkov in čustvenih simbolov doseže sodobnejši pristop, ki temelji na večjem zaupanju in lahko doseže širši krog ljudi (Marder idr., 2019). Vendar pa se pri tem pojavi potreba po vzpostavitvi načina preprečevanja potencialnih zlorab. Na primer, učitelji se s študenti predhodno dogovorijo o pravilih in pogojih uporabe čustvenčkov in čustvenih simbolov v medsebojni komunikaciji. Uporaba čustvenčkov pri socialnem inženiringu, ki temelji na formalni komunikaciji (kot so direktorske prevare), ne pripomore k uspešnosti napada. Drugače je pri napadih $\mathrm{z}$ uporabo socialnega inženiringa, ki temeljijo na neformalni komunikaciji, kot so npr. ljubezenske prevare, saj lahko vzpostavijo čustveno vez med napadalcem in potencialno žrtvijo.

Rezultati pregleda literature so sicer pokazali, da čustvenčki in čustveni simboli lahko vplivajo na uspešnost napadov $\mathrm{z}$ uporabo socialnega inženiringa, toda dokončnega odgovora na to, kako in v kolikšni meri lahko čustvenčki in čustveni simboli vplivajo na uspešnost teh napadov, še ni mogoče zaslediti. Na podlagi dosedanjih raziskav je npr. domala nemogoče ugotoviti, katere oblike čustvenčkov in čustvenih simbolov so najpogosteje uporabljene za uspešno izvedbo napadov socialnega inženiringa.

$\mathrm{V}$ nadaljevanju podajamo nekaj izhodišč za nadaljnje raziskave. Prvič, v literaturi ni mogoče zaslediti raziskav o učinkovitosti čustvenčkov v povezavi z obljubljeno materialno koristjo. Primere poskusov socialnega inženiringa je sicer mogoče najti tudi na slovenskih spletnih portalih (slika 3).

Drugič, smiselno bi bilo analizirati besedila s čustvenčki in čustvenimi simboli, ki so bila uporabljena $\mathrm{v}$ uspešnih napadih z uporabo socialnega inženiringa, ter jih primerjati z golimi besedili. Na ta način bi pridobili podrobnejši vpogled tako $\mathrm{v}$ učinek uporabe čustvenčkov kot tudi razlike med pristopoma $\mathrm{k}$ socialnemu inženiringu $\mathrm{z}$ in brez uporabe čustvenčkov. Kljub temu, da lahko čustvenčki samo obogatijo besedilo, lahko namreč z njihovo uporabo napadalci povsem spremenijo svoj "slog" komunikacije. Boljše poznavanje uporabe čustvenčkov in čustvenih simbolov bi tako pomagalo oblikovati smernice za učinkovitejšo obrambo pred tovrstnimi napadi. Tretjič, smiselno bi bilo raziskati, ali se učinkovitost uporabe čustvenčkov razlikuje glede na uporabljeno platformo (npr. Android, iOS, Windows), vrsto naprave (npr. pametni telefon, tablica, računalnik) in komunikacijski kanal (npr. e-pošta, SMS, zasebni pogovor na socialnem omrežju). Četrtič, v zadnjem času so se zaradi politične korektnosti začeli pojavljati tudi kulturno oz. rasno raznoliki čustvenčki

\section{iščem moškega za sex}

classylady

\section{$f) \rho+$}

Gospodje, iščem nekoga, ki bi me lahko potrebno damo osrečil v postelji piši na

Odgovori g פ

Slika 3. Primer socialnega inženiringa na enem izmed slovenskih spletnih portalov.
(Hankerson idr., 2016). Tako bi bilo smiselno raziskati vpliv uporabe čustvenčkov, ki upodabljajo različne rase pri socialnem inženiringu na posameznike iz pripadajoče rase (ali so temnopolti čustvenčki učinkovitejši pri napadih na temnopoltne potencialne žrtve in kakšne čustvenčke uporabijo v napadih na belopolte potencialne žrtve).

\section{Zaključek}

Čustvenčki in čustveni simboli na področju socialnega inženiringa veljajo za relativno novo področje znanstvenega raziskovanja, ki mu bo v prihodnosti veljalo posvetiti dodatno pozornost. S pomočjo sistematičnega pregleda literature smo identificirali relevantna dela, ki jih lahko umestimo na področje socialnega inženiringa. Rezultati kažejo, da je raba čustvenčkov in čustvenih simbolov v komunikaciji preko spleta primerljiva komunikaciji v živo, saj ima pošiljatelj neposreden vpliv na prejemnika, ker so čustvenčki univerzalno orodje, ki ga na podoben način razumejo vse demografske skupine. Vpliv čustvenčkov in čustvenih simbolov na čustva pa je mogoče izkoriščati pri napadih z uporabo socialnega inženiringa. Večina avtorjev pregledane literature se poslužuje spletnih anket ali eksperimentov, kar pomeni priložnost predvsem za kvalitativno raziskovanje. V pričujočem prispevku smo izpostavili teoretične in praktične implikacije na podlagi opisane problematike, ki lahko v prihodnosti služijo kot vodilo za zaščito pred socialnim inženiringom in $\mathrm{k}$ izboljšanju kibernetske in informacijske varnosti na splošno.

\section{Literatura}

Aldunate, N., Villena-González, M., Rojas-Thomas, F., López, V. in Bosman, C. A. (2018). Mood detection in ambiguous messages: The interaction between text and emoticons. Frontiers in Psychology, 9(423), 1-8.

Alshenqeeti, H. (2016). Are emojis creating a new or old visual language for new generations? A socio-semiotic study. Advances in Language and Literary Studies, 7(6), $56-69$.

Bich-carrière, L. (2019). Say it with [a smiling face with smiling eyes]: Judicial use and legal challenges with emoji interpretation in Canada. International Journal for the Semiotics of Law, 32, 283-319.

Bordbar, A., Memari, M. in Asadi, B. (2017). Introspective study of emoticon icon in public chat as a gesture of texting. Research in Applied Linguistics, 8, 176-182.

Bullée, J.-W. H., Montoya, L., Pieters, W., Junger, M. in Hartel, P. (2018). On the anatomy of social engineering attacks-A literature-based dissection of successful attacks. Journal of Investigative Psychology and Offender Profiling, 15(1), 20-45.

Burge, J. (2013). Home of emoji meanings. Pridobljeno s https://emojipedia.org/

Campbell, C. C. (2019). Solutions for counteracting human deception in social engineering attacks. Information Technology and People, 32(5), 1130-1152. 
Cheng, D. L. (2017). Do I mean what I say and say what I mean? A cross-cultural approach to the use of emoticons \& emojis in CMC messages. Fonseca, Journal of Communication, 15, 207-226.

Churches, O., Baron-Cohen, S. in Ring, H. (2009). Seeing face-like objects: An event-related potential study. NeuroReport, 20(14), 1290-1294.

D’Onfro, J. (2016). You can finally start using Facebook's new animated "Reactions" today. Business Insider. Pridobljeno s https://www.businessinsider. com/how-to-use-facebook-reactions-emoji-2016-2

Davis, P. A. (2014). Life won't be complete until we get these emojis. Pridobljeno s https://www.thecut. com/2014/06/250-new-emoji-are-coming-to-yourphone-in-july.html

Derks, D., Bos, A. E. R. in von Grumbkow, J. (2008). Emoticons in computer-mediated communication: Social motives and social context. CyberPsychology \& Behavior, 11(1), 99-101.

Duan, J., Xia, X. in Van Swol, L. M. (2018). Emoticons' influence on advice taking. Computers in Human Behavior, 79, 53-58.

Ekman, P. in Friesen, W. (1971). Constant across cultures in the face and emotion. Journal of Personality and Social Psychology, 17(2), 124-129.

Elder, A. M. (2018). What words can't say: Emoji and other non-verbal elements of technologically-mediated communication. Journal of Information, Communication and Ethics in Society, 16(1), 2-15.

Emojipedia.org. (2019). World Emoji Day. Pridobljeno s https://emojipedia.org/

Feldman, L. B., Aragon, C. R., Chen, N. C. in Kroll, J. F. (2018). Emoticons in informal text communication: A new window on bilingual alignment. Bilingualism: Language and Cognition, 21(1), 209-218.

Glikson, E., Cheshin, A. in van Kleef, G. A. (2018). The dark side of a smiley: Effects of smiling emoticons on virtual first impressions. Social Psychological and Personality Science, 9(5), 614-625.

Grannan, C. (2019). What's the difference between emoji and emoticons? Encyclopaedia Britannica. Pridobljeno s https://www.britannica.com/story/whats-the-differencebetween-emoji-and-emoticons

Grieve, R., Moffitt, R. L. in Padgett, C. R. (2019). Student perceptions of marker personality and intelligence: The effect of emoticons in online assignment feedback. Learning and Individual Differences, 69, 232-238.

Hankerson, D., Marshall, A. R., Booker, J., El Mimouni, H., Walker, I. in Rode, J. A. (2016). Does technology have race? Conference on Human Factors in Computing Systems - Proceedings, 07-12-May, 473-485.

Happ, C., Melzer, A. in Steffgen, G. (2016). Trick with treat: Reciprocity increases the willingness to communicate personal data. Computers in Human Behavior, 61, $372-377$.

Huang, A. H., Yen, D. C. in Zhang, X. (2008). Exploring the potential effects of emoticons. Information and Management, 45(7), 466-473.
Hutchinson, A. (2019). Facebook is testing new, more animated reactions. Social Media Today. Pridobljeno s https://www.socialmediatoday.com/news/facebook-istesting-new-more-animated-reactions/553595/

Ibáñez, J. (2011). Minimalist approach to show emotions via a flock of smileys. Journal of Network and Computer Applications, 34(4), 1283-1291.

Kinard, B. R. in Kinard, J. L. (2013). The effect of receipt personalization on tipping behavior. Journal of Consumer Behaviour, 12(4), 280-284.

Krombholz, K., Hobel, H., Huber, M. in Weippl, E. (2015). Advanced social engineering attacks. Journal of Information Security and Applications, 22, 113-122.

Li, X. (Shirley), Chan, K. W. in Kim, S. (2019). Service with emoticons: How customers interpret employee use of emoticons in online service encounters. Journal of Consumer Research, 45(5), 973-987.

Lin, T. J. in Chen, C. H. (2018). A preliminary study of the form and status of passionate affection emoticons. International Journal of Design, 12(2), 75-90.

Lohmann, K., Pyka, S. S. in Zanger, C. (2017). The effects of smileys on receivers' emotions. Journal of Consumer Marketing, 34(6), 489-495.

Rodrigues, D., Prada, M., Gaspar, R., Garrido, M. V. in Lopes, D. (2017). Lisbon Emoji and Emoticon Database (LEED): Norms for emoji and emoticons in seven evaluative dimensions. Behavior Research Methods, 50(1), 392-405.

Luangrath, A. W., Peck, J. in Barger, V. A. (2017). Textual paralanguage and its implications for marketing communications. Journal of Consumer Psychology, 27(1), 98-107.

Marder, B., Houghton, D., Erz, A., Harris, L. in Javornik, A. (2019). Smile(y) - and your students will smile with you? The effects of emoticons on impressions, evaluations, and behaviour in staff-to-student communication. Studies in Higher Education, 1-13.

Marengo, D., Giannotta, F. in Settanni, M. (2017). Assessing personality using emoji: An exploratory study. Personality and Individual Differences, 112, 74-78.

Matsui, T. in Kato, S. (2017). Emoticon recommendation system reflecting user individuality: A preliminary survey of emoticon use. Proceedings of the 9th International Conference on Agents and Artificial Intelligence, 459-464.

Mihelič, A., Jevšček, M., Vrhovec, S. in Bernik, I. (2019). Testing the human backdoor: Organizational response to a phishing campaign. Journal of Universal Computer Science, 25(11), 1458-1477.

Na'aman, N., Provenza, H. in Montoya, O. (2017). Varying linguistic purposes of emoji in (Twitter) context. 2nd International Conference on Knowledge Engineering and Applications, 136-141.

Njenga, K. (2017). Social media information security threats: Anthropomorphic emoji analysis on social engineering. IT Convergence and Security 2017, Lecture Notes in Electrical Engineering, 450, 185-192. 
Oleszkiewicz, A., Karwowski, M., Pisanski, K., Sorokowski, P., Sobrado, B. in Sorokowska, A. (2017). Who uses emoticons? Data from 86702 Facebook users. Personality and Individual Differences, 119, 289-295.

Pardes, A. (2018). The WIRED guide to emoji. Pridobljeno s https://www.wired.com/story/guide-emoji/

Peng, Z., Hu, Q. in Dang, J. (2019). Multi-kernel SVM based depression recognition using social media data. International Journal of Machine Learning and Cybernetics, 10(1), 43-57.

Prada, M., Rodrigues, D. L., Garrido, M. V., Cavalheiro, B., Lopes, D., Gaspar, R. (2018). Motives, frequency and attitudes toward emoji and emoticon use. Telematics and Informatics, 35(7), 1925-1934.

Prasad, A. G., Sanjana, S., Bhat, S. M. in Harish, B. S. (2017). Sentiment analysis for sarcasm detection on streaming short text data. 2017 2nd International Conference on Knowledge Engineering and Applications, ICKEA 2017, $1-5$.

Qiu, M., Feng, Y. in Yang, H. (2017). Sentence structure study of Emoji communication. Second International Symposium on Business Corporation and Development in South-East and South Asia under B\&R Initiative (ISBCD 2017), 83-86.

Riordan, M. A. (2017). The communicative role of non-face emojis: Affect and disambiguation. Computers in Human Behavior, 76, 75-86.

Salgado-Montejo, A., Salgado, C. J., Alvarado, J. in Spence, C. (2017). Simple lines and shapes are associated with, and communicate, distinct emotions. Cognition and Emotion, 31(3), 511-525.

Santos, D. in Maia, B. (2018). Language, emotion, and the emotions: A computational introduction. Linguistics and Language Compass, 12(6), 1-20.

Shaikh, S., Lalingkar, P., Barach, E. in Feldman, L. (2017). Cross-cultural reactions to crisis events via language and emoticon use. Advances in Cross-Cultural Decision Making, 1, 24-28.

Stark, L. in Crawford, K. (2015). The conservatism of emoji: Work, affect, and communication. Social Media and Society, 1(2).

Takahashi, F. in Kawabata, Y. (2018). The association between colors and emotions for emotional words and facial expressions. Color Research and Application, 43(2), 247-257.

Takahashi, K., Oishi, T. in Shimada, M. (2017). Is -) smiling? Cross-cultural study on recognition of emoticon's emotion. Journal of Cross-Cultural Psychology, 48(10), 1578-1586.

Tang, Y. in Hew, K. F. (2018). Emoticon, emoji, and sticker use in computer-mediated communications: Understanding its communicative function, impact, user behavior, and motive. V Deng, L., Will, W. K., Fong, C. W. R. (ur.), New Media for Educational Change (str. 191-201).

Thomson, S., Kluftinger, E. in Wentland, J. (2018). Are you fluent in sexual emoji? Exploring the use of emoji in romantic and sexual contexts. The Canadian Journal of Human Sexuality, 27, 1-11.
Tseng, T. H. in Hsieh, S. H. (2019). Determinants of emoticon usage in mobile instant messaging: A construal level theory perspective. Behaviour and Information Technology, 38(3), 289-301.

Vrhovec, S. (2016). Safe mobile device use in the cyberspace [Varna uporaba mobilnih naprav $\mathrm{v}$ kibernetskem prostoru]. Elektrotehniški Vestnik [Electrotechnical Review], 83(3), 144-147.

Wang, Y. (2015). For first time ever, an emoji is crowned Oxford Dictionaries' Word of the Year. The Washington Post. Pridobljeno s https://www.washingtonpost.com/ news/morning-mix/wp/2015/11/17/for-first-time-everan-emoji-is-crowned-oxford-dictionaries-word-of-theyear/?noredirect $=$ on\&utm_term $=. f f 5000361 \mathrm{~d} 15$

Weiß, M., Gutzeit, J., Rodrigues, J., Mussel, P. in Hewig, J. (2019). Do emojis influence social interactions? Neural and behavioral responses to affective emojis in bargaining situations. Psychophysiology, 1-14.

Willoughby, J. F. in Liu, S. (2018). Do pictures help tell the story? An experimental test of narrative and emojis in a health text message intervention. Computers in Human Behavior, 79, 75-82.

Wolf, A. (2000). Emotional expression online: Gender differences in emoticon use. CyberPsychology \& Behavior, 3(5), 827-833.

Woolford, S. J., Barr, K. L. C., Derry, H. A., Jepson, C. M., Clark, S. J., Strecher, V. J. in Resnicow, K. (2011). OMG do not say LOL: Obese adolescents' perspectives on the content of text messages to enhance weight loss efforts. Obesity, 19(12), 2382-2387.

Workman, M. (2008). Wisecrackers: A theory-grounded investigation of phishing and pretext social engineering threats to information security. Journal of the American Society for Information Science and Technology, 59(4), 662-674.

$\mathrm{Xu}$, L., Yi, C. in $\mathrm{Xu}, \mathrm{Y} .(2007)$. Emotional expression online: The impact of task, relationship and personality perception on emoticon usage in instant messenger. V Pacific Asia Conference on Information Systems, PACIS 2007, Auckland, New Zealand, July 4-6, 2007. 